\title{
The first non-mammalian CXCR5 in a teleost fish: molecular cloning and expression analysis in grass carp (Ctenopharyngodon idella)
}

\author{
Qiao Q Xu1,2, Ming X Chang ${ }^{1}$, Rong H Sun ${ }^{1}$, Fan S Xiao ${ }^{1}$ and P Nie*1
}

\begin{abstract}
Background: Chemokines, a group of small and structurally related proteins, mediate chemotaxis of various cell types via chemokine receptors. In mammals, seven different CXC chemokine receptors denoted as CXCR1 to CXCR7 have been reported. However, the chemokine receptor CXCR5 has not been reported in other vertebrates.

Results: In the present study, the genomic sequence of CXCR5 was isolated from the grass carp Ctenopharyngodon idella. The cDNA sequence of grass carp CXCR5 (gcCXCR5) consists of 1518 bp with a 43 bp 5 ' untranslated region (UTR) and a 332 bp 3' UTR, with an open reading frame of 1143 bp encoding 381 amino acids which are predicted to have seven transmembrane helices. The characteristic residues (DRYLAIVHA) and conserved cysteine residues are located in the extracellular regions and in the third to seventh transmembrane domains. The deduced amino acid sequence shows 37.6-66.6\% identities with CXCR5 of mammals, avian and other fish species. The grass carp gene consists of two exons, with one intervening intron, spaced over 2081 bp of genomic sequence. Phylogenetic analysis clearly demonstrated that the gcCXCR5 is clustered with those in other teleost fish and then in chicken and mammals. Realtime PCR analysis showed that gCCXCR5 was expressed in all tested organs/tissues and its expression level was the highest in trunk kidney, followed by in the spleen. The expression of gCCXCR5 was significantly modulated by immunostimulants such as peptidoglycan (PGN), lipopolysaccharide (LPS), polyinosinic-polycytidylic acid sodium salt (Poly l:C) and phytohaemagglutinin (PHA).

Conclusion: The CDNA and genomic sequences of CXCR5 have been successfully characterized in a teleost fish, the grass carp. The CXCR5 has in general a constitutive expression in organs/tissues examined, whereas its expression was significantly up-regulated in immune organs and down-regulated in brain, indicating its potential role in immune response and central nervous system.
\end{abstract}

\section{Background}

Chemokines are a family of small (8-14 kDa), inducible, structurally related proteins, which mediate chemotaxis of various cell types including neutrophils, monocytes, lymphocytes, basophils, eosinophils and fibroblasts to sites of inflammation [1] and are implicated in many biological processes, such as migration of leukocytes, embryogenesis, angiogenesis, hematopoiesis etc [2-5]. The biological activities of chemokines are mediated via chemokine receptors, which belong to a large family of

\footnotetext{
* Correspondence: pinnie@ihb.ac.cn

1 State Key Laboratory of Freshwater Ecology and Biotechnology, Institute of Hydrobiology, Chinese Academy of Sciences, Wuhan, Hubei Province 430072, PR China

Full list of author information is available at the end of the article
}

rhodopsin-like G-protein-coupled, seven transmembrane domain receptors $[6,7]$. Chemokines and their receptors were divided into four families (CXC, CC, $\mathrm{C}$, and CX3C) on the basis of cysteine residues in the ligands (here $\mathrm{C}$ represents cysteine and X/X3 represents one or three nocysteine amino acids) [1]. Recently, a system of nomenclature was introduced in which each ligand and receptor is identified by its subfamily with an identifying number [8]. Thus, there exist CCR1-11, CXCR1-7, XCR1 (the lymphotactin receptor), and CX3CR1 (the fractalkine receptor) [9].

In human and mouse, seven different $\mathrm{CXC}$ chemokine receptors denoted as CXCR1 to CXCR7 have so far been reported, and these CXC chemokine receptors have roles in chemotaxis of neutrophils, attraction of Th1 cells, or 
effector of T cell generation [10]. Genomic structure and expression of five CXCRs including CXCR1, 2, 3, 4, 7 have been characterized either in model fish and/or in economically important fish species. For example, CXCR1 has been reported in several species of fish, such as common carp Cyprinus carpio and mandarin fish Siniperca chuatsi [11,12]; CXCR2 in common carp [12]; CXCR3 in grass carp Ctenopharyngodon idella [13]; CXCR4 in sea lamprey Petromyzon marinus, zebrafish Danio rerio, common carp, rainbow trout Oncorhynchus mykiss, sterlet Acipenser ruthenus [14-18], CXCR7 in zebrafish and medaka Oryzias latipes $[19,20]$. In teleost fish, the literature on the function of CXC chemokine receptors is rather limited. It was only recently reported that two CXCR4 genes, CXCR4a and CXCR4b, isolated in zebrafish had roles in the development and migration of cranial neural crest cells [21]. Similar to CXCR4, it was demonstrated that CXCR7, which was recently revealed to recognize the chemokine, stromal cell-derived factor-1 (SDF1) [22], played an essential role in primordium migration [23], and CXCR4 and CXCR7 are antagonistic in control of cell migration in the development of the posterior lateral line [23].

CXCR5 was first reported from human Burkitt's lymphoma [24], whereafter the murine homologue of CXCR5 was cloned and its expression was found in a pattern similar to human CXCR5 [25]. In mammals, CXCR5 and its ligand CXCL13 are responsible for the organization of $\mathrm{B}$ cell follicles and the migration of $\mathrm{B}$ and $\mathrm{T}$ cells [26,27], and involved in other functions such as in the attraction of human metastatic neuroblastoma cells to the bone marrow [28]. However, CXCR5 has not been identified in any species of fish so far. In this study, CXCR5 was cloned from the grass carp $C$. idella, an important fish in aquaculture industry of China [29]. Furthermore, its expression was examined in different organs/tissues, and in response to the stimulation of peptidoglycan (PGN), lipopolysaccharide (LPS), polyinosinic-polytidylic acid sodium salt (Poly I:C) and phytohaemagglutinin (PHA).

\section{Results}

\section{Cloning and characterization of grass carp CXCR5 CDNA}

The grass carp CXCR5 (gcCXCR5) cDNA (GenBank accession no. FJ825363) consists of 1648 bp with a $43 \mathrm{bp}$ 5 ' untranslated region (UTR) and a 332 bp 3'-UTR with poly(A) addition signal (AATAAA) and two mRNA instability motifs (ATTTA). The open reading frame of gcCXCR5 cDNA encodes 381 amino acids with a calculated molecular mass of $43.34 \mathrm{kDa}$ and an isoelectric point of 8.40. Analysis of the putative amino acid sequence by TMpred program suggests that gcCXCR5 is a membrane protein with seven transmembrane helices between amino acids 65-87, 99-121, 136-155, 176-198, 230-252, 272-294 and 314-336 (Figure 1). The extracellu- lar regions of the gcCXCR5 contain four cysteines, presumably forming disulfide bonds. In the transmembrane regions TM3-TM7 existed respectively two other cysteine residues. Moreover, there are two cysteine intracellular regions at the carbon terminal. Analysis using Signal P-N program showed that gcCXCR5 has no signal peptide, but has a potential N-glycosylation sites at N34. Using the Scanprosite programs in PROSITE database http://ca.expasy.org/prosite, a sequence CGSLLLACISVDRYLAI (145-161 amino acids) containing the G-protein-coupled receptor family 1 signature was identified. It was also revealed that the gcCXCR5 sequence contains cAMP- and cGMP- dependent protein kinase phosphorylation sites (at amino acids 85-88), tyrosine kinase phosphorylation site (at amino acids 206-214), N-myristoylation sites (at amino acids 72-82, 125-130 and 215220 ), protein kinase $C$ phosphorylation sites (at amino acids 13-15, 224-226 and 255-257), and casein kinase II phosphorylation sites (at amino acids 7-10, 30-33 and 367-370) (Figure 1).

The deduced amino acid sequence of the gcCXCR5 protein was compared with other chemokine receptors by calculating the sequence identities using the MEGALIGN program. The full-length amino acid sequence of gcCXCR5 has the highest identities with zebrafish CXCR5 (66.6\%), followed by stickleback CXCR5 (53.5\%) and fugu CXCR5 (51.6\%). The identifies of gcCXCR5 with CXCR5 from human, mouse, rat and chicken are $38.8 \%, 37.8 \%, 37.6 \%$ and $37.6 \%$, respectively. The identity between gcCXCR5 and other reported chemokine receptors, CXCR1, CXCR2, CXCR3, CXCR4, CXCR6 and CXCR7, ranges among 27.3-33.2\%, 31.2-34.0\%, 35.0$43.5 \%, 27.8-30.4 \%, 26.4-28.0 \%$, and $36.5-37.1 \%$, respectively. In the phylogenetic tree based on amino-acid sequences from four CXCR1, three CXCR2, eight CXCR3, six CXCR4, seven CXCR5, two CXCR6 and four CXCR7 sequences, the gcCXCR5 was clustered closely (bootstrap value $>99 \%$ ) with CXCR5 in other fish species, and then with other CXCR5 in higher vertebrates (Figure 2), and all other CXCRs with same identified number were clustered into a same clade, except that CXCR1 and CXCR2 were clustered together.

\section{Characterization of gcCXCR5 genomic DNA}

The gcCXCR5 gene has a length of 2081 bp (GenBank accession no. FJ825364). Using BLAST2, the alignment of gcCXCR5 cDNA sequence with gcCXCR5 genomic sequence revealed that the gcCXCR5 gene is composed of two exons and one intron. The first exon is $109 \mathrm{bp}$ in length, containing a short 5'-UTR and ORF of 23 amino acids (Figure 3 ). The second exon is 1384 bp in length, coding for the all seven transmembrane domains of gcCXCR5. The intervening intron is $588 \mathrm{bp}$. The exon- 
Grass carp MFICIRTNMDLITNKVTLDLSFSIPG------------DYLSEYENVTEHPDG-VQY IC Zebrafish Fugu

Stickleback Chicken Mouse Rat Human

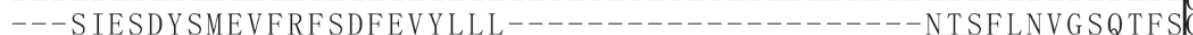

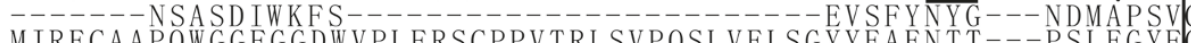
MIRECAAPQWGGFGGDWVPLFRSCPPVTRLSVPQSLVELSGYYEAENTT---PSLEG YFG

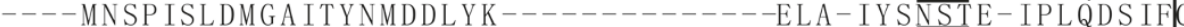
---- MNY P L T LEMD --LENLED LFW -----------ELD - RLD N Y NDT SLV - - ENHLC

46 36 26 57 40 40

TM1

Grass carp Zebrafish

Fugu

Stickleback Chicken

Mouse

Rat

Human

ENEKNPLHL-----FHTVFQPLVYGVVFLLGLTGNGLLLTVLLKRRSNLR ITE IYLLHLA IRAKRCGPSLEQS-FRATFESLFY SCLLLLGVLG NGLUVIVLL KRRHNLR ITE IYLLHLA DDE-GISLR------TFQPVLYSL IFLLGVSG NGLMT TLL LRRRHHLR ITE IYLLHLA FNPSSLWLANQRDPFRKVF IPLA YLLMFVLGTVQ NALVLV IL ERFKRSRTTTENF LFHLT STVEGPLLTS----FKAVFMPVAYSL IFLLGMMGN ILVLV IL ERHRHTR SSTETFLFHLA STEEGPLLTS----FKT IFMPVAYSL IFLLGMMG ILVLV IL ERHRHTRSSTETFLFHLA PATEGPLMAS----FKAVFVPVAYSL IFLLGVIG NVLVLV IL ERHRQTRSSTETFLFHLA

\section{TM2}

\section{TM3}

Grass carp

Zebrafish

Fugu

Stickleback

Chicken

Mouse

Rat

Human

LADLLLLFTFPFAVTQGAAGWLFGTF ICKLLGL INRLNLMCGSLLLACISVDRYLA IVHA

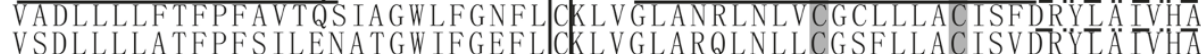

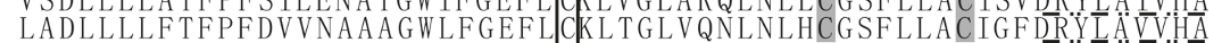
LANLALLLTFPFSVVESLAGWVFGTFLCK ILSA VHK INFYLHEHAAGLHRVDRY A IVYA

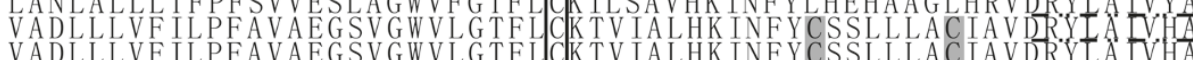

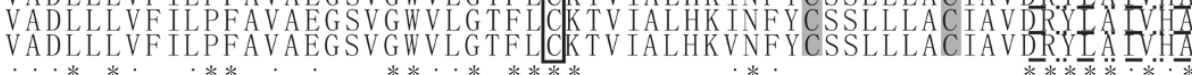

TM4

Grass carp Zebrafish

Fugu

Stickleback Chicken Mouse Rat

Human

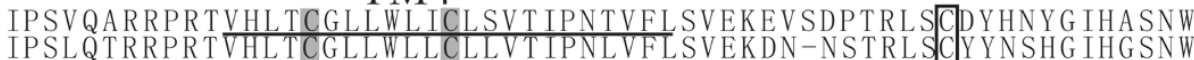
VASLQRQRRRT VHLTCTALW M VCLA ISAPNLVFLTVTGDANSSR-LSCSFDDYG IHANNW IPRM QSRCPK TVHRTC IALW LVCLGLSVPNA VF LSVK--EVGGQ-VSCF Y HDYG IHANNW IHTYRKARARS IHLT CTA IW LSSLLLTLPDL IFMEVW TDESNRS I--CYFPEAG IHGNNV VHA YRRRRLLS IH ITCTA IWLAGFLFALPELLFAK VGQPHNNDSLPQCTF SQENEAETRA VHAYRRRRLLSIH ITCST IWLAGFLFALPELLFAK VVQPHNNESLPQCIFSQENEAETRA VHA YRHRR LLS IH ITCG T IW L V GF L L A L PE ILFAK V SQGHHNNSLPRCT F SQENQAETHA

TM5

\section{TM6}

Grass carp Zebrafish Fugu

Stickleback Chicken Mouse Rat

Human

LL TSRELTHLLCFELPLAIMGYCYTSIIT LCQSQR SLEKQGA IRLALLVTLVECLCWLP
KLTSHFTTH-LCFFLPLVTMGYCYTFVV TLRQSHRSLEKQGA TRLALLFTVVFCLCWLP ALTMRVLEH-VCFFLPLA IMGSCYAAVVG TLLKSARGQTQLAA IKLALLITLVFCVCWLP VLTNTVLNH-VCFF IPLA VMSYCYAA V V V TLCRSQKSQAKQGA IRLSLLVTLVFFFCWLP WLATRFLYHSVGFFMPLLVMCYCYMA IVRTLCQSQR-LQRQKAVRVA ILVT GVFLLCWSP

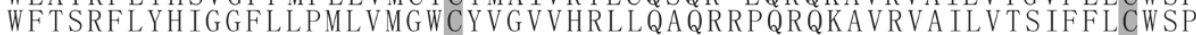
WFASRFLYHTGGFLLPMLVMAWCYVGVVHRLLQAQRRPQRQKAVRVA ILVT S IF LLCWSP WF TSRF L Y HV A G F L L P LVMGWCY V GVVHRLRQAQRRPQRQKAVRVA ILVTS IFF LCW SP

\section{TM7}

Grass carp YNTTVFMHTLVVLGVMPEQDCHAHDTLNRALLVTESTGFSHCCLNPIIYAFTGVRFRRDL Zebrafish

Fugu YNLT ILMNTLVDLFAMPKISCPAQDTLDRAVIVTESTGFSHCCINPILYAFIGVRFRRDI YNVASVLQTRDNLST DPSR SCESVLLLQA L V V TKSLGFSHCCLNPFLYAFVGVRFRREL

Stickleback Chicken

Mouse

Rat

Human 作 YHIV IF LNTLTKLEAFAK - DCLLEDHLDTA IMV TEA IGFTHCCLNP I I YAF IG VKFR DDF YH IV IF LDTLERLKA VNS-SCELSGYLSVA I TLCEFLGLAHCCLNPMLYTFAGVKF SDI YH IV IF LDTLER L KAVN - SCELSGYLSVA I TCEFLG LAHCCLNPMLYTFAGVKFR SDL YH IV IF LD TLARLKA VDN - TCKLNGSLPVA I TMCEFLGLAHCCLNPMLY TFAGVKFRSDL

LQLLAK TKCLRA---CLSGLQRKSLNRMS ITEA IT T T T SSQY I 381

Stickleback

Chicken

LQLLAKTKCLRV---CFSDVR INNLNRVSVTDAVTTT T---- - 313

LRLLSKAGC- - - - -

Mouse SRLLTKLGCAGPASLCQLFPNWR---KSSLSESENATSLTTF- 374

Rat

SRLLTKLGCAGPASLCQLFPGWR---KSSLSESENATSLTTF- 374

SRLLTKLGCTGPASLCQLFPGWR---RSSLSESENATSLTTF- 372

Figure 1 The alignment of the amino acid sequences of gcCXCR5 (GenBank accession no. FJ825363) with CXCR5 sequences of other vertebrates by using CLUSTAL W program. Symbol (*) represents identical residues, (:) conservative substitution, (.) similar residues and (-) missing residues. The seven transmembrane domains are underlined, cysteines in the transmembrane domains are indicated by gray shadow and the conserved four cysteines presumably forming disulfide bonds are boxed. Broken underline indicates sequence DRYLAIVHA and uninterrupted underline NXS/T indicates $\mathrm{N}$-glycosylation site. The sequences of CXCR5 used for analysis are derived from the GenBank, with their accession numbers listed in Table 2. 


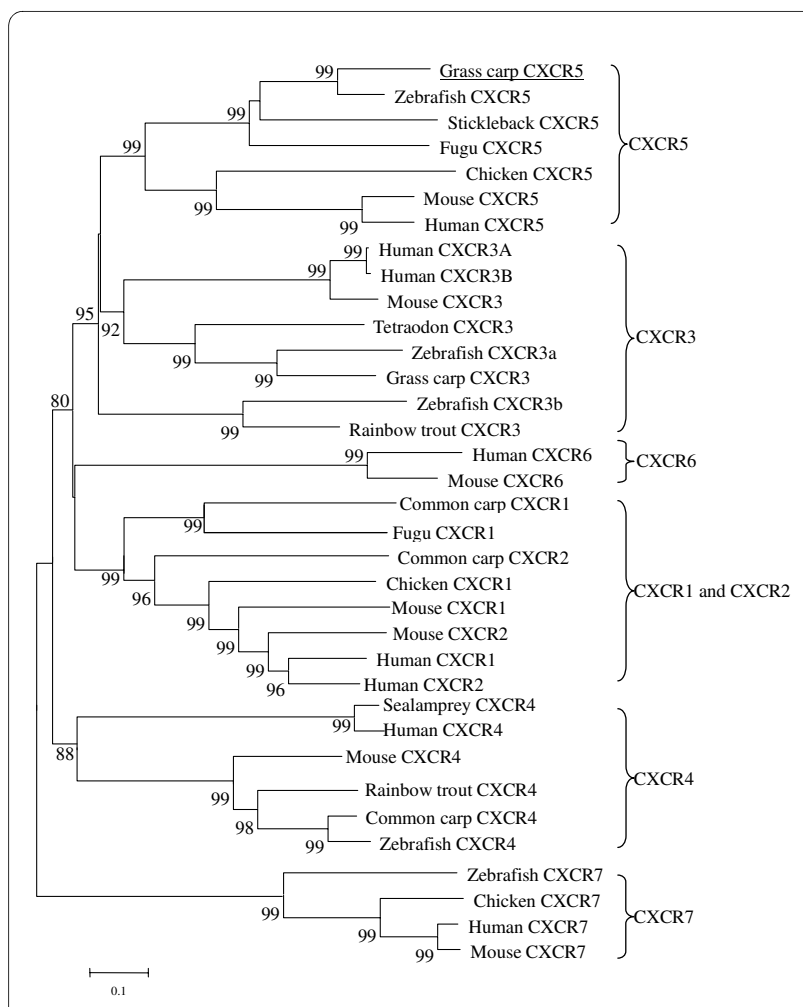

Figure 2 Phylogenetic relationship of CXCR members. A neighborjoining phylogenetic tree of chemokine receptor sequences was constructed based on analysis of protein sequences by the computer program CLUSTER W. The sequences of the CXCR used for analysis are derived from the GenBank and SwissProt, and their accession numbers are listed in Table 2. The bootstrap confidence values shown at the nodes of the tree are based on 1000 bootstrap replications. Homo sapiens, Human; Mus musculus, Mouse; Gallus gallus, Chicken; Danio rerio, Zebrafish; Cyprinus carpio, Common carp; Ctenopharyngodon idella, Grass carp; Oncorhynchus mykiss, Rainbow trout; Petromyzon marinus, Sea lamprey; Tetraodon nigroviridis, Tetraodon; Takifugu rubripes, Fugu; Gasterosteus aculeatus, Stickleback.

intron junction follows the consensus rule of the splice donor and acceptor sites for splicing (Figures 1 and 3).

\section{Expression of gcCXCR5}

In normal fish, the expression of gcCXCR5 was observed in all the organs/tissues examined, with strong expression in trunk kidney, spleen, intestine, head kidney, brain, muscle, but almost undetectable expression in liver and heart (Figure 4).

As shown in Figure 5, PGN injection significantly induced gcCXCR5 expression in spleen, thymus and trunk kidney, decreased expression in brain, gill, liver and blood $(P<0.05)$, but no significant difference in other organs/tissues $(P>0.05)$. LPS stimulation significantly increased gcCXCR5 expression in spleen, trunk kidney, blood, intestine and head kidney $(P<0.05)$, but decreased expression in brain $(P<0.05)$, with no significant difference in other organs/tissues $(P>0.05)$. The induced

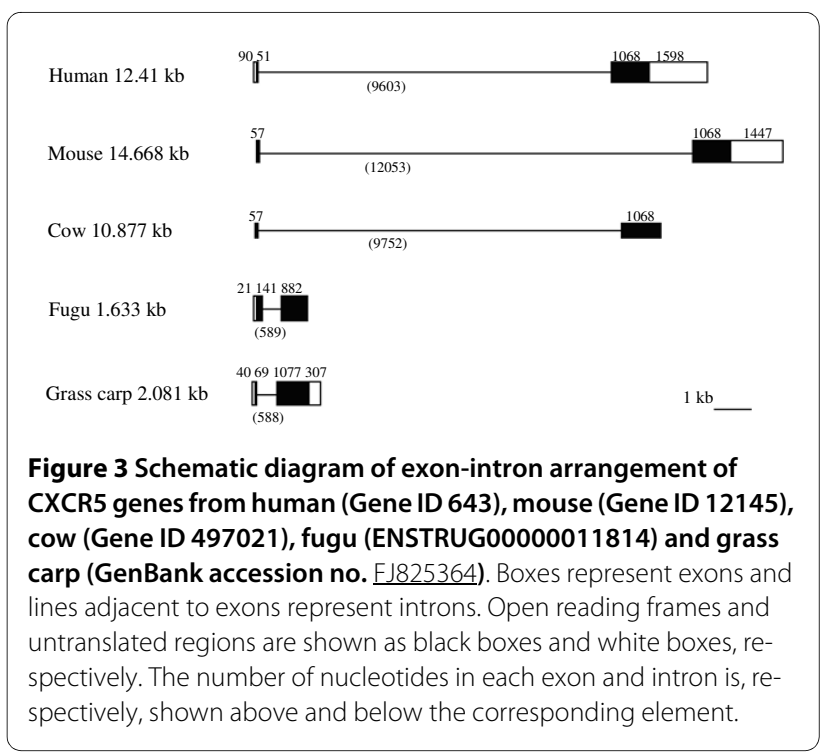

expression of gcCXCR5 by Poly I:C was observed in trunk kidney, head kidney and gill $(P<0.05)$, decreased expression in brain and blood $(P<0.05)$. PHA significantly induced gcCXCR5 in most organs/tissues $(P<0.05)$ except brain and liver. The decreased expression of gcCXCR 5 by PHA was observed in brain $(P<0.05)$.

\section{Discussion}

CXCR5, also known as BLR1, has been identified as a member of the lymphocyte-specific GPCR family [30]. The present study for the first time reported the cDNA and genomic sequences of CXCR5 and its expression pattern in a teleost fish, the grass carp. In general, the sequences of chemokine receptors have $25-80 \%$ aa identity. However, many other G-protein-coupled peptide

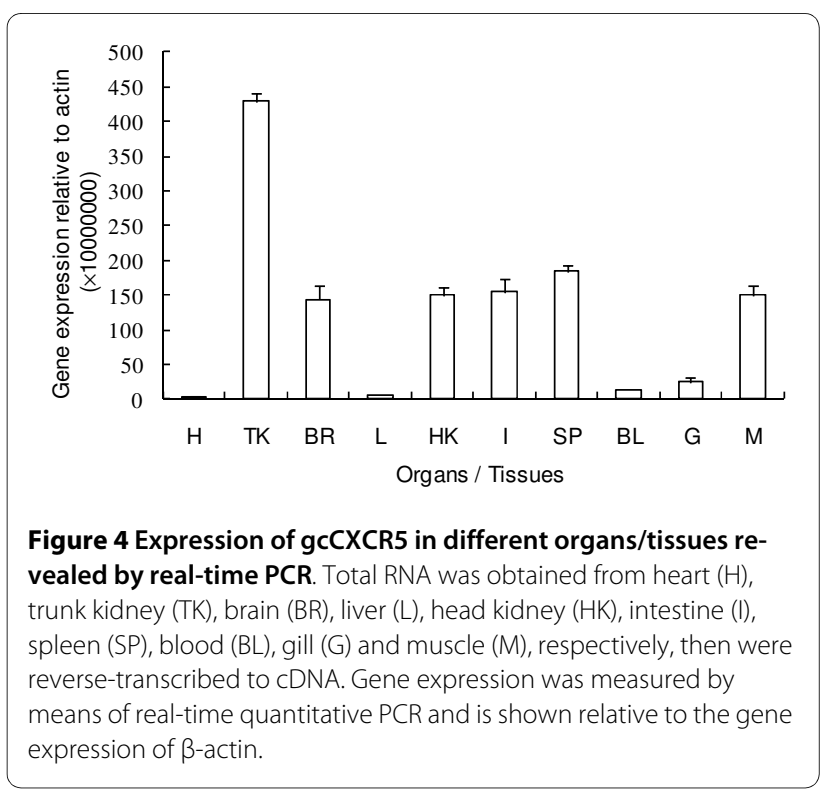



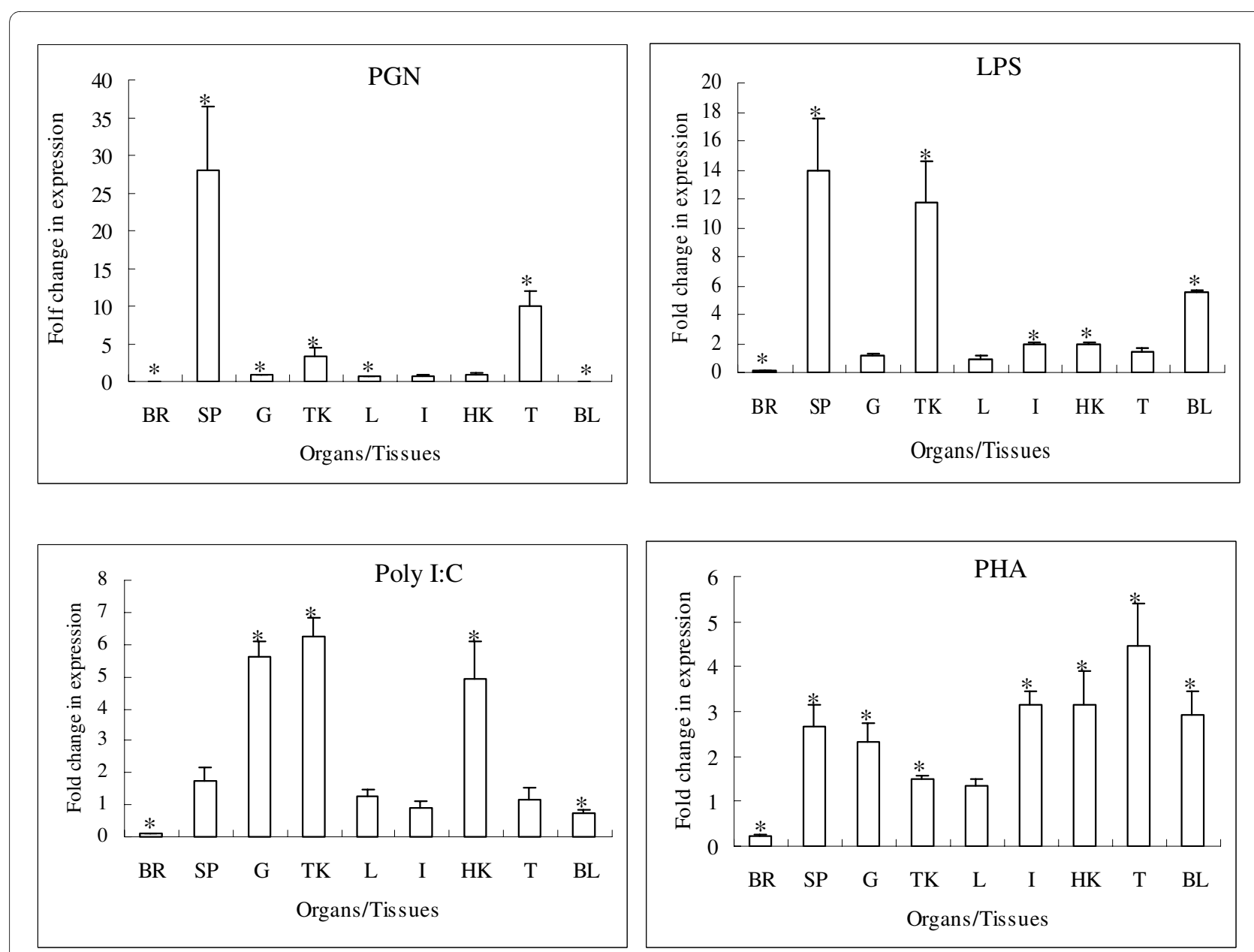

Figure 5 Expression pattern of grass carp CXCR5 gene induced by peptidoglycan (PGN), lipopolysaccharide (LPS), polyinosinic-polycytidylic acid sodium salt (Poly I:C) and phytohaemagglutinin (PHA) in vivo. Total RNA was obtained from brain (BR), spleen (SP), gill (G), trunk kidney (TK), liver (L), intestine (I), head kidney (HK), thymus (T) and blood (BL), respectively. The transcriptional changes are shown in ratio in comparison with control fish, as determined by quantitative real-time PCR. Each column and bar represents the mean \pm SE of three individual fish.

receptors (GPCRs) also have around $25 \%$ aa identity with chemokine receptors, suggesting that the structural boundary is not very sharp. Although they lack a single structural signature, there are several features that together are found more frequently among chemokine receptors than in other types of GPCRs. These include a length of 340-370 aa, an acidic N-terminal segment, the sequence DRYLAIVHA or a variation of it in the second intracellular loop, a short basic third intracellular loop, and a cysteine in each of the four extracellular domains. In addition, chemokine receptors contain numerous serines and threonines in the C-terminal tail that become phosphorylated after receptor-ligand interaction [8,31]. The sequence of gcCXCR5 contains all these characters except for the length of amino acid sequences. The alignment of gcCXCR5 amino acid sequence with CXCR5 sequences from other vertebrates revealed some conserved structural features. The presence of N-linked gly- cosylation sites at $\mathrm{N}$-terminus and/or in the second extracellular loop is a common feature of chemokine receptors, as recognized by other authors [7,13,32], and all the CXCR5s including gcCXCR5 contain a conserved $\mathrm{N}$-linked glycosylation sites at $\mathrm{N}$ terminus. Furthermore, the close phylogenetic relationship between gcCXCR5 and zebrafish CXCR5, and then other teleost fish CXCR5 may indicate their close evolutionary relationship. This, together with other CXCR members, i.e., CXCR3, CXCR4, CXCR5, CXCR6, which were clustered respectively into different clades, may reveal to some extent the conservation of these members in vertebrates, except that CXCR1 and CXCR2 were clustered in a same clade, as shown also by other reports [22,33], which may imply a similar evolutionary origin of these two receptors.

Similar to the genomic structures of CXCR5 in fugu (ENSTRUG00000011814), human (Gene ID 643), mouse (Gene ID 12145) and cow (Gene ID 497021), the 
gcCXCR5 consists of two exons and one intron. Compared with the size of mammalian CXCR5 genomic sequences, fish CXCR5 is much smaller in length. Despite the difference in genomic size, vertebrate CXCR5 have similar size in exons.

In mammals, much effort has been focused on identifying CXCR5 expression in different organs/tissues and also in cell types [25,30]. Murine homologue of CXCR5 has been described as being expressed in lymphoid organs, and murine CXCR5-specific RNA is detected consistently at low levels in secondary lymphatic organs. The CXCR5 gene is expressed regularly and strongly in lymphomas of mature B cells but not in plasmacytomas $[25,30]$. In the present study, constitutive expression of CXCR5 was observed abundantly in trunk kidney, spleen, head kidney, intestine, muscle and brain. In vivo, grass carp CXCR5 expression was up-regulated mainly in immune organs such as spleen, trunk kidney, head kidney and blood, suggesting the potential function of gcCXCR5 in immune response. The induced expression of gcCXCR5 in a wider range of organs/tissues containing lymphocytes was consistent with the function of mammalian CXCR5, as reported to attract $\mathrm{T}$ lymphocytes $[26,27]$. The immunostimulants used in the present study include PGN, LPS and Poly I:C, which are derived from Gram-positive bacteria, Gram-negative bacterial endotoxin and a synthetic double stranded RNA (dsRNA) mimicking viral dsRNA, respectively; and phytohaemagglutinin (PHA), known to cause leucocyte agglutination and to stimulate the proliferation of lymphocytes [34]. The modulated difference of gcCXCR5 by different immunostimulants may be owing to the effect of different pattern recognition receptors (PRRs) which recognize different bacterial and/or viral elements on different cell types.

On the other hand, it is difficult to explain the downregulation of gcCXCR5 expression in brain after PGN, LPS, Poly I:C and PHA stimulation. However, the higher expression of gcCXCR5 in brain was similar to gcCXCR3 which also had abundant expression in brain [13]. Based on the observation in mammals that CXCR2, CXCR3 and CXCR4 were expressed in central nervous system by neurons and microglial cells etc [31,35-37], it is suggested that brain chemokine receptors may promote the recruitment of haematopoietic cells from circulation, both as part of normal surveillance and immunological control within the brain, and as a component of the inflammatory response [38]. Whether this is the case for fish CXCR5 and other fish CXCRs requires further study.

In addition, CXCR5 may be modulated by other cytogenes. Krumbholz et al. [39] reported that about 20\% of CSFCD4 ${ }^{+}$cells and almost all B cells expressed the CXCL13 receptor CXCR5. In vitro, CXCL13 was produced by monocytes and at a much higher level by mac- rophages. CXCL13 mRNA and protein expression was induced by TNF alpha and IL-1beta but inhibited by IL-4 and IFN gamma [39]. However, it would be interesting to know if this is the case in fish.

\section{Conclusions}

In summary, gcCXCR5 consists of $1518 \mathrm{bp}$, encoding 381 amino acids which are predicted to have seven transmembrane helices. The characteristic residues (DRYLAIVHA) and conserved cysteine residues are located predominantly in the extracellular regions and in the third to seventh transmembrane domains. The gcCXCR5 was expressed in all tested organs/tissues. The expression of gcCXCR5 was significantly modulated by peptidoglycan, lipopolysaccharide, polyinosinic-polycytidylic acid sodium salt and phytohaemagglutinin.

\section{Methods}

\section{Cloning of cDNA and genomic sequences}

Based on the zebrafish and Tetraodon sequences of CXCR5 homologues from Ensembl website, one pair of degenerate primers $\mathrm{F} 1$ and $\mathrm{R} 1$ were designed to obtain the internal region of gcCXCR5. The PCR cycling conditions were 1 cycle of $94^{\circ} \mathrm{C}$ for $5 \mathrm{~min}, 35$ cycles of $94^{\circ} \mathrm{C}$ for $30 \mathrm{~s}, 57^{\circ} \mathrm{C}$ for $30 \mathrm{~s}$ and $72^{\circ} \mathrm{C}$ for $30 \mathrm{~s}$, followed by $1 \mathrm{cycle}$ of $72^{\circ} \mathrm{C}$ for $10 \mathrm{~min}$. The resultant product was isolated using the Gel Extraction Kit (Omega, USA), cloned into pMD18-T vector (TaKaRa, Japan) and transformed into Escherichia coli strain M15 competent cells by following the manufacturer's instruction. Putative clones were screened by PCR using the above primers under the same PCR cycle conditions, and the selected clones were sequenced. To obtain the full-length cDNA sequence of gcCXCR5, 5' RACE and 3' RACE were performed by using the gene-specific primers and adaptor primers. The universal primers mix (UPM) was the mixture of the long form (UPM Long) and short form (UPM Short).

For the first 3'-RACE, the PCR was initially performed with primers UPM/3-F1 followed by a nested PCR with primers UPM/3-F2. The annealing temperature of first and second $\mathrm{PCR}$ was $63^{\circ} \mathrm{C}$ and $65^{\circ} \mathrm{C}$, respectively. For the second $3^{\prime}-\mathrm{RACE}$, the PCR was performed with primers UPM/3-F3 followed by a nested PCR with primers UPM/ 3-F4. The annealing temperature of first and second PCR was $63^{\circ} \mathrm{C}$ and $66^{\circ} \mathrm{C}$, respectively.

For $5^{\prime}$-RACE, first strand cDNA synthesis is primed using a gene-specific antisense primer (5-R1). Following cDNA synthesis, the first strand product is purified from unincorporated dNTPs and 5-R1. TdT (Terminal deoxynucleotidyl transferase) is used to add homopolymeric tails to the 3 ' ends of the cDNA. Tailed cDNA is then amplified by PCR using gene-specific antisense primer (5-R2) and 5' abridged anchor primer (AAP). The annealing temperature of $\mathrm{PCR}$ was $55^{\circ} \mathrm{C}$. A dilution of the origi- 
nal PCR (0.1\%) was re-amplified using a gene-specific antisense nested primer (5-R3) and abridged universal amplification primer (AUAP). The annealing temperature of PCR was $65^{\circ} \mathrm{C}$. All primers are listed in Table 1 .

The genomic DNA was purified from trunk kidney of healthy grass carp using Wizard Genomic DNA Purification Kit (Promega). Based on the full-length cDNA sequence, D-F1 and D-R1 were designed to obtain the full-length genomic sequence of gcCXCR5. PCR was performed using the primer pairs listed in Table 1.

\section{Sequence analysis}

Protein prediction was performed using software at the ExPASy Molecular Biology Server http://www.expasy.ch/. The putative ORFs were analyzed for the presence of signal peptides using the algorithms Signal P 3.0. The intron/exon structure of the identified genomic sequence was determined by alignment of the full-length cDNA to the genomic sequence using BLAST2 http://www.ncbi.nlm.nih.gov/ blast/bl2seq/wblast2.cgi. The transmembrane regions were identified by the Tmpred http://www.cbs.dtu.dk/ services/TMHMM/. Putative domains and the G-protein-coupled receptors family 1 signature were identified by PROSITE http://ca.expasy.org/prosite. A multiple alignment was generated using the CLUSTAL W program. Sequence identities were calculated using the MEGALIGN program within DNASTAR. Phylogenetic analysis was performed using the neighbor-joining method within the Mega molecular evolutionary genetic analysis software package. Data were analyzed using Poisson correction, and gaps were removed by pairwise deletion. The degree of confidence for each branch point was determined by bootstrap analysis (1,000 times). All the sequences used for the phylogenetic analysis are listed in Table 2 .

\section{RNA extraction and cDNA synthesis for expression analysis} Grass carp, 200 to $300 \mathrm{~g}$ in body weight, were obtained in Niushan lake, Wuhan, Hubei Province, China. After seven-day acclimatization in a quarantine tank, heart,

Table 1: Oligonucleotide primers used to amplify the gcCXCR5 gene

\begin{tabular}{|c|c|c|}
\hline Name & Sequence (5'-3') & Usage \\
\hline $\mathrm{F} 1$ & ATCTACCTGCTA(G)CAC(T)CTGGC & Cloning for the internal fragment \\
\hline $\mathrm{R} 1$ & AGCAGC(G)TGC(G)AGCAGGTCG(T)C(T)T & \\
\hline UPM Long & CTAATACGACTCACTATAGGGCAAGCAGTGGTATCAACGCAGAGT & Race-PCR Universal primers \\
\hline UPM Short & CTAATACGACTCACTATAGGGC & \\
\hline AAP & GGCCACGCGTCGACTAGTACGGGIIGGGIIGGGIIG & 5' RACE Abridged Primer \\
\hline AUAP & GGCCACGCGTCGACTAGTAC & \\
\hline $5-\mathrm{R} 1$ & GGTTCCAAAAAGCCA & 5'RACE $1^{\text {st }}$ round $P C R$ \\
\hline $5-\mathrm{R} 2$ & CTTGAGTAACTGCGAATGGAAA & 5'RACE $2^{\text {nd }}$ round PCR \\
\hline $5-\mathrm{R3}$ & GAGCAGGTCAGCCAGTGCCAGAT & $5^{\prime} \mathrm{RACE} 3^{\text {rd }}$ round PCR \\
\hline $3-\mathrm{F} 1$ & GTITTCTGCCTGTGCTGGCTACCG & $3^{\prime} R A C E 1^{\text {st }}$ round $P C R$ \\
\hline $3-F 2$ & CCCTGGTAGTGTTGGGTGTTATGCC & $3^{\prime} R A C E 2^{\text {nd }}$ round PCR \\
\hline $3-\mathrm{F3}$ & CCGTITCCGAAGAGACCTCCTGC & $3^{\prime} R A C E 1^{\text {st }}$ round $P C R$ \\
\hline $3-\mathrm{F} 4$ & GCCATTACTACCACAACAAGCAGC & $3^{\prime} R A C E 2^{\text {nd }}$ round PCR \\
\hline $\mathrm{D}-\mathrm{F} 1$ & TGGACGAGGACACACACTTCTGAG & For intron \\
\hline D-R1 & GCCGTITAGCAGGACTGTCAAGAG & \\
\hline$\beta$-actinF & CCTTCTTGGGTATGGAGTCTTGAGAGTATITACGCTCAGGTGGG & Real-time quantitative PCR control \\
\hline \multicolumn{3}{|l|}{$\beta$-actinR } \\
\hline RT-F1 & GTGTTGGGTGTTATGCCTGAGATGTATTGGCTGCTTGTTGTG & Real-time quantitative PCR \\
\hline RT-R1 & & \\
\hline
\end{tabular}


Table 2: The accession numbers of chemokine receptor sequences used for phylogenetic tree construction and multiple sequence alignment

\begin{tabular}{|c|c|c|c|c|c|}
\hline Species & Gene & Accession no. & Species & Gene & Accession no. \\
\hline \multirow[t]{8}{*}{ Homo sapiens } & CXCR1 & NP 000625 & Gallus gallus & CXCR1 & NP 001026762 \\
\hline & CXCR2 & NM 001557 & & CXCR5 & NP 001026083 \\
\hline & CXCR3A & P49682 & & CXCR7 & NM 001083362 \\
\hline & CXCR3B & NP 001136269 & Danio rerio & CXCR3a & NP 001082899 \\
\hline & CXCR4 & NP 001008540 & & CXCR3b & NP 001007315 \\
\hline & CXCR5 & NP 001707 & & CXCR4 & NP 571909 \\
\hline & CXCR6 & NP 006555 & & CXCR5 & $\underline{X P} 002665447$ \\
\hline & CXCR7 & NP 064707 & & CXCR7 & NM 001083832 \\
\hline \multirow[t]{7}{*}{ Mus musculus } & CXCR1 & NP 839972 & Cyprinus carpio & CXCR1 & BAA31458 \\
\hline & CXCR2 & NM 009909 & & CXCR2 & BAA31470 \\
\hline & CXCR3 & NP 034040 & & CXCR4 & BAA32797 \\
\hline & CXCR4 & NP 034041 & Ctenopharyngodon idella & CXCR3 & AAW69766 \\
\hline & CXCR5 & NP 031577 & & CXCR5 & FJ825363 \\
\hline & CXCR6 & NP 109637 & Oncorhynchus mykiss & CXCR3 & CAC86390 \\
\hline & CXCR7 & NP 031748 & & CXCR4 & NP 001117814 \\
\hline Rattus norvegicus & CXCR5 & NP 445755 & Takifugu rubripes & CXCR1 & NP 001072110 \\
\hline Tetraodon nigroviridis & CXCR3 & CAF98051 & & CXCR5 & ENSTRUG00000011814 \\
\hline Petromyzon marinus & CXCR4 & AAO21209 & Gasterosteus aculeatus & CXCR5 & ENSGACG00000012278 \\
\hline
\end{tabular}

trunk kidney, brain, liver, head kidney, intestine, spleen, blood, gill and muscle from three grass carp were used for RNA isolation using Trizol reagent (Invitrogen, USA) in order to analyze the expression of gcCXCR5 in healthy grass

carp.

To study the effect of different immunostimulants on the expression of gcCXCR5, four stimulants with different origins and different functions were chosen. Phytohaemagglutinin (PHA) is an extract from plant with roles in stimulating lymphocyte proliferation, lipopolysaccharide (LPS) and peptidoglycan (PGN) were derived from Gram- negative and positive bacteria, respectively, while Poly I:C mimics virus. Five groups of fish (three fish each) were injected with either $500 \mu \mathrm{l}$ PBS, $500 \mu \mathrm{l} \mathrm{PGN}(1 \mathrm{mg} /$ $\mathrm{ml}), 500 \mu \mathrm{l}$ PHA $(1 \mathrm{mg} / \mathrm{ml}), 500 \mu \mathrm{l}$ Poly I:C $(2 \mathrm{mg} / \mathrm{ml})$, or $500 \mu \mathrm{l}$ LPS $(2 \mathrm{mg} / \mathrm{ml})$. Twenty-four hours after injection, total RNA was extracted using TRIzol reagent (Gibco) as described by the manufacturer from organs/tissues of 
interest, including brain, spleen, gill, trunk kidney, liver, intestine, head kidney, thymus and blood from both injected and control groups.

After treatment with RNase-free DNase I, $2 \mu \mathrm{g}$ of total RNA was reverse-transcribed respectively with Revert Aid TM First Strand cDNA Synthesis Kit (Fermentas). All cDNA samples were stored at $-20^{\circ} \mathrm{C}$ until used in realtime PCR assays.

\section{Real-time quantitative PCR}

Primer premier 5.0 was used for designing forward and reverse primers. The primers which performed best in real-time PCR were: gcCXCR5 Forward (RT-F1), Reverse (RT-R1); $\beta$-actin Forward ( $\beta$-actin F), Reverse ( $\beta$-actin R) (Table 1). The annealing temperatures for gcCXCR5 and $\beta$-actin were $58^{\circ} \mathrm{C}$, and resultant amplicons of both were 266 and $221 \mathrm{bp}$, respectively. The gcCXCR5 and $\beta$-actin cDNA fragments were generated by PCR. Amplicons were gel-purified, cloned into pMD18-T vector and transformed into Escherichia coli strain DH5 $\alpha$ competent cells. Cloned amplicon sequences were confirmed by sequencing. Plasmid DNA was obtained by using the Plasmid mini kit I (Omega) by following the manufacturer's instructions. Serial tenfold dilutions of plasmid DNA were used in PCR for establishing a standard curve. PCR reactions were performed using Chromo $4^{\text {mi }}$ Continuous Fluorescence Detector from MJ Research. Amplifications were carried out at a final volume of $20 \mu \mathrm{l}$ containing $1 \mu \mathrm{l}$ DNA sample, $10 \mu \mathrm{l} 2 \times$ SYBR green Real time PCR Master Mix (Toyobo, Japan), $2 \mu \mathrm{l}$ of each primer and $5 \mu \mathrm{l} \mathrm{H}_{2} \mathrm{O}$. PCR amplification consisted of 5 min at $95^{\circ} \mathrm{C}$, followed by 45 cycles consisting of $10 \mathrm{~s}$ at $94^{\circ} \mathrm{C}, 15 \mathrm{~s}$ at $58^{\circ} \mathrm{C}, 20 \mathrm{~s}$ at $72^{\circ} \mathrm{C}$ and plate-reading at $80^{\circ} \mathrm{C}$. The reaction carried out without DNA sample was used as control. Melting curve analysis of amplification products was performed at the end of each PCR reaction to confirm that a single PCR product was detected. Each sample was run in triplicate. Standard curves were run on the same plate.

Statistical analysis was performed using a one-way analysis of variance (ANOVA). A probability level of $P<$ 0.05 was considered significant. Fold change was calculated as $(\mathrm{Ts} / \mathrm{Tn}) /(\mathrm{Cs} / \mathrm{Cn})$ where Ts equals the treated sample assayed for the specific gene and Tn equals the treated sample assayed for $\beta$-actin gene, and $\mathrm{Cs}$ and $\mathrm{Cn}$ equal the calibrator group with the specific and normalizing gene, respectively [40]. All statistical analyses were based on comparisons between the control and injection groups.

\section{Authors' contributions}

XQQ carried out the experiments and drafted the manuscript. CMX participated in the study design and in the manuscript preparation. SRH cloned partial sequence. XFS was involved in the experiment. NP was responsible for overall project and finalized the manuscript. All authors read and approved the final manuscript.

\section{Acknowledgements}

The research was financially supported by a project (2009CB118703) of National Basic Research Program of China (973 Program)

\section{Author Details}

1State Key Laboratory of Freshwater Ecology and Biotechnology, Institute of Hydrobiology, Chinese Academy of Sciences, Wuhan, Hubei Province 430072 PR China and 2 School of Animal Science, Yangtze University, Jingzhou, Hubei Province 434025, PR China

Received: 27 August 2009 Accepted: 26 May 2010 Published: 26 May 2010

\section{References}

1. Zlotnik A, Yoshie O: Chemokines: a new classification system and their role in immunity. Immunity 2000, 12:121-127.

2. Baggiolini M: Chemokines and leukocyte traffic. Nature 1998, 392:565-568.

3. Kanbe K, Shimizu N, Soda Y, Takagishi K, Hoshino H: A CXC chemokine receptor, CXCR5/BLR1, is a novel and specific coreceptor for human immunodeficiency virus type 2 . Virology 1999, 265:264-273.

4. Luster AD: Chemokines-chemotactic cytokines that mediate inflammation. N Engl J Med 1998, 338:436-445.

5. Struyf S, Proost P, Van Damme J: Regulation of the immune response by the interaction of chemokines and proteases. Adv Immunol 2003, 81:1-44

6. Murphy PM: The molecular biology of leukocyte chemoattractant receptors. Annu Rev Immunol 1994, 12:593-633.

7. Murphy PM: Chemokine receptors: structure, function and role in microbial pathogenesis. Cytokine Growth Factor Rev 1996, 7:47-64.

8. Murphy PM, Baggiolini M, Charo IF, Hebert CA, Horuk R, Matsushima K, Miller LH, Oppenheim JJ, Power CA: International union of pharmacology. XXII. Nomenclature for chemokine receptors. Pharmacol Rev 2000, 52:145-176.

9. Zlotnik A, Morales J, Hedrick JA: Recent advances in chemokines and chemokine receptors. Crit Rev Immunol 1999, 19:1-47.

10. Oliveira SH, Lukacs NW: The role of chemokines and chemokine receptors in eosinophil activation during inflammatory allergic reactions. Braz J Med Biol Res 2003, 36:1455-1463.

11. Chen C, Li Z, Zhou Z, Yin Z, Chan SM, Yu XQ, Weng S, He J: Cloning, characterization and expression analysis of a CXCR1-like gene from mandarin fish Siniperca chuatsi. Fish Physiol Biochem 2009, 35:489-499.

12. Huising MO, Stolte E, Flik G, Savelkoul HF, Verburg-van Kemenade BM: CXC chemokines and leukocyte chemotaxis in common carp (Cyprinus carpio L.). Dev Comp Immunol 2003, 27:875-888.

13. Chang MX, Sun BJ, Nie P: The first non-mammalian CXCR3 in a teleost fish: gene and expression in blood cells and central nervous system in the grass carp (Ctenopharyngodon idella). Mol Immunol 2007, 44:1123-1134

14. Alabyev BY, Najakshin AM, Mechetina LV, Taranin AV: Cloning of a CXCR4 homolog in chondrostean fish and characterization of the CXCR4 specific structural features. Dev Comp Immunol 2000, 24:765-770.

15. Chong SW, Emelyanov A, Gong Z, Korzh V: Expression pattern of two zebrafish genes, cxcr4a and cxcr4b. Mech Dev 2001, 109:347-354.

16. Daniels GD, Zou J, Charlemagne J, Partula S, Cunningham C, Secombes CJ: Cloning of two chemokine receptor homologs (CXC-R4 and CC-R7) in rainbow trout Oncorhynchus mykiss. J Leukoc Biol 1999, 65:684-690.

17. Fujiki K, Shin DH, Nakao M, Yano T: Molecular cloning of carp (Cyprinus carpio) CC chemokine, CXC chemokine receptors, allograft inflammatory factor-1, and natural killer cell enhancing factor by use of suppression subtractive hybridization. Immunogenetics 1999, 49:909-914

18. Kuroda N, Uinuk-ool TS, Sato A, Samonte IE, Figueroa F, Mayer WE, Klein J: Identification of chemokines and a chemokine receptor in cichlid fish, shark, and lamprey. Immunogenetics 2003, 54:884-895.

19. Perlin JR, Talbot WS: Signals on the move: chemokine receptors and organogenesis in zebrafish. SCiSTKE 2007 :pe45.

20. Sasado T, Yasuoka A, Abe K, Mitani H, Furutani-Seiki M, Tanaka M, Kondoh $\mathrm{H}$ : Distinct contributions of CXCR4b and CXCR7/RDC1 receptor systems in regulation of $\mathrm{PGNC}$ migration revealed by medaka mutants kazura and yanagi. Dev Biol 2008, 320:328-339. 
21. Killian ECO, Birkholz DA, Artinger KB: A role for chemokine signaling in neural crest cell migration and craniofacial development. Dev Biol 2009, 333:161-172.

22. Balabanian K, Lagane B, Infantino S, Chow KY, Harriague J, Moepps B, Arenzana-Seisdedos F, Thelen M, Bachelerie F: The chemokine SDF-1/ CXCL12 binds to and signals through the orphan receptor RDC1 in T lymphocytes. J Biol Chem 2005, 280:35760-35766.

23. Dambly-Chaudière C, Cubedo N, Ghysen A: Control of cell migration in the development of the posterior lateral line: antagonistic interactions between the chemokine receptors CXCR4 and CXCR7/RDC1. BMC Dev Biol 2007, 7:23.

24. Dobner T, Wolf I, Emrich T, Lipp M: Differentiation-specific expression of a novel $\mathrm{G}$ protein-coupled receptor from Burkitt's lymphoma. Eur $J$ Immunol 1992, 22:2795-2799.

25. Kaiser E, Forster R, Wolf I, Ebensperger C, KuehI WM, Lipp M: The G protein-coupled receptor BLR1 is involved in murine B cell differentiation and is also expressed in neuronal tissues. Eur I Immunol 1993, 23:2532-2539.

26. Ansel KM, McHeyzer-Williams LJ, Ngo VN, McHeyzer-Williams MG, Cyster JG: In vivo-activated CD4 T cells upregulate CXC chemokine receptor 5 and reprogram their response to lymphoid chemokines. J Exp Med 1999, 190:1123-1134.

27. Hardtke S, Ohl L, Forster R: Balanced expression of CXCR5 and CCR7 on follicular Thelper cells determines their transient positioning to lymph node follicles and is essential for efficient B-cell help. Blood 2005, 106:1924-1931.

28. Airoldi I, Cocco C, Morandi F, Prigione I, Pistoia V: CXCR5 may be involved in the attraction of human metastatic neuroblastoma cells to the bone marrow. Cancer Immunol Immunother 2008, 57:541-548.

29. Li SF, Lu QQ, Zhou BY: Evaluation on the potential capacity of the swan oxbow for the conservation of the major Chinese carps. Aquaculture 1995, 137:46-47.

30. Forster R, Wolf I, Kaiser E, Lipp M: Selective expression of the murine homologue of the G-protein-coupled receptor BLR1 in B cell differentiation, $B$ cell neoplasia and defined areas of the cerebellum. Cell Mol Biol 1994, 40:381-387.

31. Bajetto A, Bonavia R, Barbero S, Florio T, Schettini G: Chemokines and their receptors in the central nervous system. Front Neuroendocrino 2001, 22:147-184

32. Strader CD, Fong $T M$, Tota MR, Underwood D, Dixon RA: Structure and function of G protein-coupled receptors. Annu Rev Biochem 1994, 63:101-132.

33. Goostrey A, Jones $G$, Secombes CJ: Isolation and characterization of CXC receptor genes in a range of elasmobranchs. Dev Comp Immunol 2005, 29:229-242.

34. Sodomann CP, Rother M, Havemann K, Martini GA: Lymphocyte proliferation to phytohaemagglutinin ( $\mathrm{PHA}$ ) in hepatitis $\mathrm{B}$ antigen positive and -negative hepatitis. Res Exp Med 1979, 175:95-107.

35. Horuk R, Martin AW, Wang Z, Schweitzer L, Gerassimides A, Guo H, Lu Z, Hesselgesser J, Perez HD, Kim J, Parker J, Hadley TJ, Peiper SC: Expression of chemokine receptors in subsets of neurons in the central nervous system. J Immunol 1997, 158:2882-2890.

36. Lavi E, Strizki JM, Ulrich AM, Zhang W, Fu L, Wang Q, O'Connor M, Hoxie JA, Gonzalez-Scarano F: CXCR-4 (Fusin), a co-receptor for the type 1 human immunodeficiency virus (HIV-1), is expressed in the human brain in a variety of cell types, including microglia and neurons. Am J Pathol 1997, 151:1035-1042.

37. Xia M, Bacskai BJ, Knowles RB, Qin SX, Hyman BT: Expression of the chemokine receptor $C X C R 3$ on neurons and the elevated expression of its ligand IP-10 in reactive astrocytes: In vitro ERK1/2 activation and role in Alzheimer's disease. J Neuroimmunol 2000, 108:227-235.

38. Martín-García J, Kolson DL, González-Scarano F: Chemokine receptors in the brain: their role in HIV infection and pathogenesis. AIDS 2002, 16:1709-1730.

39. Krumbholz M, Theil D, Cepok S, Hemmer B, Kivisakk P, Ransohoff RM Hofbauer M, Farina C, Derfuss T, Hartle C, Newcombe J, Hohlfeld R, Mein E: Chemokines in multiple sclerosis: CXCL12 and CXCL13 up-regulation is differentially linked to CNS immune cell recruitment. Brain 2006, 129:200-211.

40. Purcell MK, Kurath G, Garver KA, Herwig RP, Winton JR: Quantitative expression profiling of immune response genes in rainbow trout following infectious haematopoietic necrosis virus (IHNV) infection or DNA vaccination. Fish Shellfish Immunol 2004, 17:447-462.

doi: $10.1186 / 1471-2172-11-25$

Cite this article as: Xu et al., The first non-mammalian CXCR5 in a teleost fish: molecular cloning and expression analysis in grass carp (Ctenopharyngodon idella) BMC Immunology 2010, 11:25

\section{Submit your next manuscript to BioMed Central and take full advantage of:}

- Convenient online submission

- Thorough peer review

- No space constraints or color figure charges

- Immediate publication on acceptance

- Inclusion in PubMed, CAS, Scopus and Google Scholar

- Research which is freely available for redistribution
C Biomed Central 